\title{
JUVENTUDE CIBORGUE E A TRANSGRESSÃO DAS FRONTEIRAS DE GÊNERO
}

\author{
Shirlei Rezende Sales \\ Universidade Federal de Minas Gerais \\ Marlucy Alves Paraíso \\ Universidade Federal de Minas Gerais
}

\begin{abstract}
Resumo: Pessoas e máquinas estão cada vez mais conectadas por meio de um processo de intensa simbiose. As/os jovens são o alvo primordial desse processo, constituindo a subjetividade ciborgue. Este artigo analisa o processo de ciborguização da juventude na interface entre currículo escolar e currículo do Orkut (site de relacionamentos). A pesquisa que subsidia este artigo investigou a interface entre o currículo de uma escola pública de ensino médio e as comunidades e os perfis no Orkut das/os alunas/os dessa escola. O referencial teórico é constituído pelos estudos de gênero e de currículo, em uma perspectiva pós-crítica. O argumento desenvolvido é o de que as estratégias utilizadas em um currículo podem ser traduzidas no outro, por meio da interface entre eles, tendo como efeito ora a transgressão, ora o fortalecimento das fronteiras de gênero.
\end{abstract}

Palavras-chave: juventude ciborgue; gênero; currículo; Orkut.

\section{Introdução}

A contemporaneidade tem sido marcada pela intensa conexão entre as pessoas e as máquinas.' Essas conexões trazem muitas questões para o campo educacional, que se vê com a incumbência de analisar as implicações produzidas pela inserção cada vez mais crescente das denominadas tecnologias digitais na vida das pessoas. A juventude é sem dúvida um ícone nesse processo. É ela que cada vez mais interage com as tecnologias

Copyright (c) 2011 by Revista Estudos Feministas.

'Este artigo consiste em um recorte da pesquisa de doutorado que tem por título Orkut.com.escol@: currículos e ciborguização juvenil, de autoria de Shirlei Rezende Sales, sob a orientação da prof.a Marlucy Alves Paraíso. 
e, nessa interação, vai se produzindo, conduzindo a própria existência e se tornando a cada dia mais ciborguizada. Afinal, ao se vincularem às tecnologias, as/os jovens vão formando híbridos tecnoculturais: as/os ciborgues.

Este artigo traz fragmentos dos discursos do currículo escolar e do currículo do Orkut para analisar o processo de produção de subjetividades juvenis na interface desses discursos e discutir como esses currículos têm ensinado modos de ser e de conduzir a própria conduta a muitas/os jovens brasileiras/os. O referencial teórico é constituído pelos estudos de gênero e de currículo, em uma perspectiva pós-crítica. $O$ trabalho argumentativo é desenvolvido com base em uma pesquisa que investigou tanto um currículo de uma escola pública de ensino médio como fóruns, ${ }^{2}$ tópicos ${ }^{3}$ e scraps $^{4}$ postados nas comunidades e nos perfis no Orkut das/os alunas/os dessa escola. O Orkut é um site de relacionamentos que se autodefine como "uma comunidade on-line criada para tornar a sua vida social e a de seus amigos mais ativa e estimulante". ${ }^{5}$

O Orkut é hoje o segundo endereço eletrônico mais acessado no Brasil, perdendo apenas para o buscador Google, o qual lidera também o ranking mundial de acessos. ${ }^{6}$ Orkut aqui é compreendido como possuindo um currículo cultural, o qual é definido como parte de uma "pedagogia cultural" que, "de maneira mais ampla, nos ensina comportamentos, procedimentos, hábitos, valores, e atitudes, considerados adequados e desejáveis, através de diferentes artefatos, como o cinema, a televisão, as revistas, a literatura, a moda, a publicidade, a música etc.". ${ }^{7}$

Este trabalho discute o processo de produção de subjetividades ciborgues generificadas, na interface dos discursos do currículo escolar e do currículo do Orkut, e analisa como esses currículos têm ensinado modos de ser e de conduzir a própria conduta a muitas/os jovens brasileiras/os. O argumento desenvolvido é o de que as estratégias utilizadas em um currículo podem ser traduzidas no outro, por meio da interface entre eles, tendo como efeito ora a transgressão, ora o fortalecimento das fronteiras de gênero. Interface é aqui compreendida como "uma superfície de contato, de tradução, de articulação entre dois espaços, duas espécies, duas ordens de realidade diferentes: de um código para outro, do analógico para o digital, do mecânico para o humano". ${ }^{8}$

As subjetividades são aqui compreendidas como permanentemente produzidas por meio de diferentes práticas e exercícios postos em ação nos discursos a que os indivíduos têm acesso. Esses discursos estão repletos de marcadores sociais relativos a variadas dimensões como classe social, raça, etnia, sexualidade, religião, localidade, profissão, gênero etc. Dessas dimensões, gênero constitui uma importante marca da subjetividade, pois "é a instância onde e por meio da qual os seres humanos aprendem a se converter em e a se reconhecer como homens e mulheres". 9

Gênero, conforme explicita Scott, ${ }^{10}$ é "um elemento constitutivo de relações sociais baseadas nas diferenças percebidas entre os sexos" e é também "uma forma primária de dar significados às relações de poder". Como gênero é uma categoria relacional, ${ }^{11}$ tanto

\footnotetext{
${ }^{2}$ O fórum é a instância de debate de determinadas temáticas e consiste em uma das formas de se participar efetivamente das comunidades.

${ }^{3}$ Tópicos são temas a serem debatidos nos fóruns das comunidades.

${ }^{4}$ Recados deixados para as/os usuárias/os.

${ }^{5}$ ORKUT, 2009.

${ }^{6}$ ALEXA, 2009.

7 PARAÍSO, 2001 , p. 144.

${ }^{8}$ Pierre LÉVY, 1993, p. 181.

9 Dagmar MEYER, 1996, p. 48.

10 Joan SCOTT, 1995, p. 86.

11 Robert CONNELL, 1995; Guacira Lopes LOURO, 1995; e SCOTT, 1995.
}

536 Estudos Feministas, Florianópolis, 19(2): 535-548, maio-agosto/201 1 
as garotas vão ter seus modos de ser descritos, analisados e julgados, como também os rapazes. Elas e eles vão aprendendo nas lições curriculares como se portar para ser homem e ser mulher na sociedade contemporânea. Aprendem o que é valorizado, o que tem status de verdade, o que é permitido e proibido em termos de gênero. Como argumenta Scott, ${ }^{12}$ "gênero torna-se implicado na concepção e na construção do próprio poder". Nesse sentido, as relações de gênero também vão compor os jogos de poder presentes na produção das subjetividades juvenis ciborguizadas.

Nos discursos investigados, algumas subjetividades demandadas posicionam as garotas como inferiores aos rapazes: a jovem burra, incapaz, inábil, irracional, que não participa de jogos eletrônicos, que não é competitiva etc. Juntamente com essas subjetividades é possível identificar outras em que as jovens transgridem as fronteiras de gênero, como as garotas que gostam de futebol, as que jogam Dota ${ }^{13}$ e vencem um rapaz etc. O processo de produção das subjetividades femininas está diretamente relacionado com a construção de masculinidades. ${ }^{14}$ Assim, nos discursos analisados demanda-se a masculinidade hegemônica do jovem que não sente dor, não se emociona, sabe Matemática, domina a tecnologia, é competitivo, é fanático por futebol e por jogos eletrônicos.

Contudo, como os discursos e as tecnologias de subjetivação são heterogêneos, nos discursos analisados também é demandado o jovem emotivo, aquele que sente saudades e pode até chorar por isso. Todo esse processo é regulado por relações de poder que atuam na avaliação dos comportamentos, de modo a buscar corrigir aquelas condutas culturalmente definidas como inadequadas. Desse modo, no desenvolvimento deste artigo, inicialmente discutimos como a jovem que joga Dota transpõe as fronteiras de gênero. Em seguida analisamos como a jovem jogadora de futebol ora é descrita como uma ameaça às relações de gênero socialmente construídas, ora é por elas ameaçada. Por fim, discutimos como a subjetividade do jovem emotivo é construída de modo a transgredir a masculinidade hegemônica.

\section{A jogadora de Dota: competitividade e domínio tecnológico ameaçadores}

Currículo escolar e cibercultura: o jogo eletrônico Dota - $2^{\circ}$ ano

Regularmente, um grupo de sete alunos mata aula para ir para uma lan house,

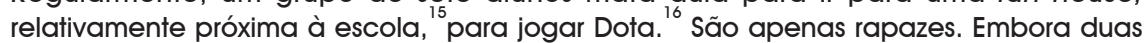
alunas, Regina (15 anos) e Cristiane (16 anos), de vez em quando acompanhem os garotos, elas não jogam Dota. Jogam outros games, ${ }^{17}$ mexem no Orkut ou conversam no MSN. ${ }^{18}$

\footnotetext{
${ }^{12}$ SCOTT, 1995, p. 88.

${ }^{13}$ Jogo eletrônico que será descrito posteriormente.

14 Pablo SCHARAGRODSKY, 2007.

$15 \mathrm{O}$ percurso a pé demora aproximadamente 40 minutos.

16 "DotA (Defense of the Ancients) é um mapa de Warcraft 3 Frozen Throne onde 2 times (Sentinel e Scourge), de até 5 jogadores cada, devem destruir a base inimiga ao mesmo tempo que defendem a sua base. Cada jogador controla um herói dos 89 possíveis (e aumentando conforme surgem novas atualizações), sendo que cada herói possui 4 habilidades únicas. Além disso, durante o jogo você pode carregar no seu herói até 6 itens simultaneamente, itens que você compra nas lojas na base e monta com receitas (os mais fortes). Seu herói começa no level 1 e você deve ir ganhando experiência para evoluir de level e obter novas habilidades, você ganha experiência matando os creeps e os adversários. Cada jogo dura em média 1hr" (DOTA BRA, 2008).

${ }^{17}$ Jogos.

${ }^{18}$ Notas do diário de campo, em 10 de julho de 2007.
} 
A inserção das/os jovens na cibercultura é intensa. No caso dessa turma observada durante a investigação que subsidia este artigo, é bastante frequente as/os alunas/os conversarem sobre variados recursos tecnológicos, games, internet, linguagens de programação, velocidades de processamento etc. O Dota é "um vício" para esse grupo de sete alunos. Há inclusive uma comunidade do Orkut, Dota Allstars - Coltec, criada por um aluno dessa turma de $2^{\circ}$ ano. Ela traz a seguinte descrição.

Se vc joga DOTA (ou ja ouviu falar de DOTA) e estuda no coltec... Se vc e fascinado por DOTA e estuda no coltec... Se vc pensa em DOTA na hora da aula e estuda no coltec... Se vc mata aula pra joga DOTA e estuda no coltec... Se vc sonha com DOTA e estuda no coltec.... Se vc... bom... alguma coisa de DOTA e estuda no coltec... Bom, essa é a sua comu!!!

Apenas 12 rapazes participam dessa comunidade. A ausência das garotas pareceunos instigante e questionamos em um tópico: "Meninas e Dota. Oi galera, queria saber por que só os meninos jogam Dota?". A resposta de Tomaz, aluno do $3^{\circ}$ ano, foi a seguinte:

Boa pergunta! um dia acho q a Regina e a Cristiane ate foram na lan, mas acho $\mathrm{q}$ isso atrai mais aos meninos mesmo o.0. ${ }^{20}$ Mas eu nunca vi uma menina jogar dota de verdade mesmo... deve ser tipo o mesmo motivo pq nao se ve um menino jogando barbie de super nintendo, sei la!

Embora as garotas não participem da comunidade, algumas também jogam e, segundo um aluno, uma delas teria inclusive vencido um dos rapazes em certa partida. A ciborguização vai se produzindo de modo a romper com as fronteiras culturalmente produzidas. Ciborgue significa justamente "fronteiras transgredidas, potentes fusões e perigosas possibilidades". ${ }^{22}$ Desse modo, mesmo o Dota sendo um jogo culturalmente atribuído aos rapazes, certas garotas se interessam por ele e assumem a posição de verdadeiras doteiras. ${ }^{23}$ Desenvolvem tamanha habilidade que chegam a vencê-los em algumas partidas.

Contudo, é evidente que o mundo dos jogos eletrônicos é descrito como dividido em termos de gênero. Parece haver uma lógica generificada de separação dos games. Se, por um lado, Dota é considerado um jogo impróprio às garotas, por outro, o jogo da Barbie é divulgado como inadequado aos rapazes.

Ainda sobre o Dota, o interesse diferenciado em termos de gênero é assim analisado:

Se vc for pensar direito, nao eh soh dota, todo tipo de jogo normalmente o publico maior sao homens, ainda mais jogos com guerra, porrada e tal...

Isso eh uma questao cultural, nao vem da nossa geraçao, vem de toda uma sociedade machista aonde apenas os homens participam deste tipo de atividade, como muitas outras coisas... é claro que existem excessoes, e isto esta mudando lentamente, mas em geral eh assim como eu disse mesmo.

Mas eh como o futebol, por exemplo, no começo era uma coisa estritamente masculina hoje ja ha ate uma liga profissional feminina do esporte no mundo, apesar de no brasil nao ser tao difundido e nem ter tanto apoio a times e tal, mas ja esta mudando com o tempo...

\footnotetext{
19 ORKUT, 2009.

${ }^{20} \mathrm{Em}$ internetês, representa uma expressão de espanto.

21 ORKUT, 2009.

22 Donna HARAWAY, 2000, p. 50.

${ }^{23}$ Doteiras/os são aquelas/es que jogam Dota.
}

538 Estudos Feministas, Florianópolis, 19(2): 535-548, maio-agosto/201 1 
Quem sabe nossas netas nao joguem dota versao 158.9c normalmente heaheahueahu aehueahu. $^{24}$ (Tomaz, 17 anos) $^{25}$

O machismo da sociedade é identificado, mas isso é imputado a uma questão cultural, o que, de certa forma, o naturaliza. Chama muito a atenção o fato de a explicação mais recorrente para as diferenças entre os gêneros ser sempre atribuída à cultura. Por mais paradoxal que isso possa parecer, trata-se de um uso da cultura para justificar uma desigualdade e não problematizá-la ou questioná-la. Percebe-se uma concepção tradicional em que a cultura "é abstraída de seu processo de produção e torna-se simplesmente uma coisa: ela é reificada". ${ }^{26}$ Nessa perspectiva, as relações de poder são desconsideradas na produção cultural, já que não se considera que a cultura é produzida como relações sociais assimétricas e desiguais. ${ }^{27} \mathrm{O}$ fato de isso não ser um privilégio dessa geração dá mais força à naturalização da diferença. As possibilidades de mudanças são remetidas para daqui a duas gerações, no mínimo.

Esse processo de naturalização das desigualdades faz parte de uma tecnologia de governo que transforma o que é estrategicamente desejável em algo normal e natural. ${ }^{28}$ Nesse sentido, a restrição das mulheres a viverem determinadas práticas, a desenvolverem certas habilidades e a competirem em alguns jogos é algo que interessa ao governo das relações de gênero e, portanto, é descrito como natural. Naturalizadas, as posições desiguais em termos de gênero tendem a ser mantidas.

O interesse dos rapazes por jogos eletrônicos como o Dota faz parte de um "regime de verdade" 29 da nossa cultura que atrela a masculinidade à competitividade, à violência ${ }^{30}$ e ao domínio da tecnologia. ${ }^{31}$ O mesmo interesse é dito como não natural às garotas e algo que talvez coloque em risco sua feminilidade. Gostar desse jogo, ter habilidade nele, jogar intensivamente, ser um viciado, tudo isso é apresentado como próprio ao rapaz e incompatível com as garotas.

Essa verdade é contestada pela juventude ciborgue, a qual se posiciona de modo diferente. Afinal, "o ciborgue é uma criatura de um mundo pós-gênero" que não se fascina por qualquer "totalidade orgânica" nem pela "unidade original, da identificação com a natureza". ${ }^{2}$ Desse modo, algumas jovens também se aventuram pelo mundo da tecnologia e da violência e jogam Dota. "Com o ciborgue, a natureza e a cultura são reestruturadas: uma não pode mais ser o objeto de apropriação ou de incorporação pela outra". ${ }^{33}$

Embora se admita que algumas garotas disputem o jogo, o "verdadeiro" gênero da doteira é colocado em dúvida. "Eu já joguei com "meninas", no entanto "não tinha como eu comprovar né...." (Cauã, 16 anos). ${ }^{35}$ As aspas na palavra "meninas" consiste em uma técnica para instaurar a dúvida sobre a autenticidade da informação. Mesmo porque, no ciberespaço, se podem fazer inusitadas composições, viver múltiplas fusões, inventar tudo

\footnotetext{
${ }^{24} \mathrm{Em}$ internetês, essa é uma das formas de expressar uma gargalhada.

25 ORKUT, 2009.

${ }^{26}$ Tomaz Tadeu da SILVA, 2001, p. 14.

27 SILVA, 2001.

${ }^{28}$ Valerie WALKERDINE, 1995.

${ }^{29}$ Michel FOUCAULT, 2004

${ }^{30}$ Fátima CECCHETTO, 2004.

${ }^{31}$ CONNELL, 1995.

32 HARAWAY, 2000 , p. 42.

33 HARAWAY, 2000 , p. 43

${ }^{34} \mathrm{Em}$ internetês, representa uma expressão de dúvida.

35 ORKUT, 2009.
} 
sobre si, inclusive o próprio gênero. A estratégia acionada por algumas garotas de jogar Dota transgride a fronteira do que é estabelecido culturalmente como normal, o que provoca o "questionamento social" 36 de seu gênero. Esse processo baseia-se em uma "penalizante insistência de que formas de masculinidade e feminilidade devem ser estabelecidas como rigidamente opostas, como desvinculadas do processo de construção social". ${ }^{37}$ As condutas das garotas e dos rapazes são analisadas dentro de um quadro que tenta fixar modos de ser homens e mulheres, em que as diferenças são apresentadas como naturais e permanentes.

Ao contrário, quando se analisam as diferenças de gênero como produzidas cultural e historicamente, evidenciam-se as relações de poder envolvidas nesse processo. Mostrase, assim, que "a idéia de natureza foi ela própria fabricada e está intimamente conectada com um processo profundo e minucioso de governo". ${ }^{38}$ Desse modo, o fato de grande parte das jovens não se interessarem por jogos eletrônicos como o Dota insere-se em um processo de governo das relações de gênero que tenta limitar as possibilidades das mulheres e dos homens, estabelecendo fronteiras entre o que é feminino e o que é masculino.

No entanto, com o procedimento de acompanhar os garotos à lan house, algumas jovens invadem um ambiente frequentado, em sua maioria, por rapazes e acionam a estratégia de romper a fronteira do espaço culturalmente destinado aos garotos. No entanto, ao mesmo tempo que transgridem, também aderem ao que é estabelecido culturalmente e não se arriscam a jogar o game considerado impróprio às garotas. Esse comportamento atua na demarcação das fronteiras de gênero e na sua reafirmação. Com isso, introduz-se uma ambivalência à medida que as jovens se posicionam entre a ciborguização transgressora e a manutenção conservadora das relações de gênero. Não há, portanto, uma categorização geral e irredutível dos comportamentos juvenis, pois "não existe nenhum impulso nos ciborgues para a produção de uma teoria total; o que existe é uma experiência íntima sobre fronteiras - sobre sua construção e desconstrução". ${ }^{39}$

A subjetividade da jovem doteira constitui-se em uma ameaça às vigentes configurações de gênero, em que os homens são apresentados como mais habilidosos no domínio das tecnologias. Esse processo discursivo de naturalização das desigualdades de gênero age sobre as condutas juvenis de modo que as garotas sejam julgadas e desqualificadas em sua capacidade de jogar e de competir com os rapazes.

Episódio do currículo escolar: aula de Educação Física - $1^{\circ}$ ano

O professor divide a turma em um grupo de meninos e outro de meninas para o exercício de treinamento de determinada modalidade esportiva. Enquanto a turma fazia a atividade proposta pelo professor, ele fazia várias observações comigo, argumentando e tentando comprovar como as garotas são menos competitivas que os rapazes.

Enunciações sobre as "mulheres serem menos competitivas" funcionam como uma verdade que circula intensivamente na sociedade brasileira contemporânea. Circula na televisão, no cinema, na literatura, nos jornais, nas conversas informais entre amigas/os, no Orkut e também na escola. Esses discursos produzidos e divulgados em nossa cultura, e que fazem parte da escola e do ciberespaço, contribuem para produzir modos de ser e de viver a feminilidade e a masculinidade considerados adequados. Esses discursos operam como uma forma essencializada de ver e dizer o feminino e o masculino como se fossem

\footnotetext{
${ }^{36}$ Deborah BRITZMAN, 1996.

${ }^{37}$ BRITZMAN, 1996, p. 77

${ }^{38}$ WALKERDINE, 1995, p. 220

${ }^{39}$ HARAWAY, 2000, p. 107.

${ }^{40}$ Notas do diário de campo, em 12 de setembro de 2007
} 
atributos inatos e universais. Isso acaba divulgando um padrão de homem e de mulher que se coloca como a referência, a partir da qual as diferentes formas de viver a feminilidade e a masculinidade são avaliadas, medidas e hierarquizadas. A/o ciborgue, no entanto, vem confundir essas fronteiras de modo que algumas garotas também entram na arena da competitividade e participam de jogos culturalmente atribuídos aos rapazes como o Dota e o futebol.

\section{A jogadora de futebol: subjetividade ameaçadora ou ameaçada?}

Episódio do currículo escolar: aula de Educação Física - $1^{\circ}$ ano Ao final da aula, que foi treinamento de futsal, o professor leva as alunas a uma autorreflexão e pede que elas analisem "se merecem a mesma nota que os meninos", que, ao contrário delas, participaram de toda a aula.

O exercício da autorreflexão é utilizado para modificar o comportamento das alunas e aumentar a participação delas na aula de Educação Física. Por meio da nota, busca-se produzir nelas o desejo da participação na aula. Algumas/alguns pesquisadoras/es já têm argumentado que, "nas aulas de Educação Física, o corpo se converte em um terreno de disputa, no qual múltiplos significados se inscrevem sobre ele, configurando uma determinada cultura somática". ${ }^{42}$ Tanto o esporte, de maneira geral, quanto a própria Educação Física parecem ser acionados como "espaços de intervenção na educação dos cidadãos, no sentido da valorização do corpo esteticamente belo e do aperfeiçoamento físico de corpos saudáveis e aptos, capazes de enfrentar desafios da vida modernizada". ${ }^{43}$ Tudo isso atua na divulgação do esporte e da Educação Física como práticas imprescindíveis a todas/os.

No processo de construção das subjetividades generificadas nas aulas de Educação Física do currículo escolar, são utilizadas determinadas estratégias, as quais permitem que "o professor ou professora exercite um olhar escrutinador sobre cada estudante, corrigindo sua conduta, sua postura física, seu corpo, enfim, examinando-o/a constantemente". ${ }^{44}$ Contudo, não são apenas as/os professoras/es que avaliam e julgam as condutas das/os alunas/os nas aulas. As/os estudantes também se avaliam mutuamente. Isso foi visto em uma aula do currículo escolar que tinha como objeto uma prática esportiva culturalmente atribuída aos rapazes: futebol.

O futebol no Brasil é uma espécie de esporte obrigatório aos rapazes, sendo-lhes ensinado desde muito cedo. Eles são, portanto, reiteradamente treinados e assim vão construindo certa habilidade com o manejo da bola. O que, via de regra, não acontece com as garotas, as quais, quando vêm a jogar futebol, o fazem mais tardiamente. Esse esporte é, pois, culturalmente considerado como de domínio masculino. Talvez por isso o pouco interesse das garotas pela aula em questão.

Além disso, a presença feminina no mundo dos esportes representa tanto uma ameaça quanto uma complementaridade. Ela é uma ameaça porque "chama para si a atenção de homens e mulheres, dentro de um universo construído e dominado por valores masculinos e porque põe em perigo algumas características tidas como constitutivas da sua

\footnotetext{
${ }^{41}$ Notas do diário de campo, em 3 de abril de 2007.

42 SCHARAGRODSKY, 2007, p. 24.

${ }^{43}$ Silvana Vilodre GOELLNER, 2000, p. 79.

44 LOURO, 1997, p. 75.
} 
feminilidade". ${ }^{45}$ É uma complementaridade porque "a mulher é parceira do homem em atitudes e hábitos sociais cujo exercício simboliza um modo moderno e civilizado de ser". ${ }^{46}$ E, embora a prática esportiva seja demandada a todas/os, há uma generificação das modalidades esportivas. Há aquelas apresentadas como mais adequadas às mulheres $e$ outras como mais adequadas aos homens, como o futebol.

Por um lado, a feminilidade da jovem jogadora de futebol consiste em uma ameaça à masculinidade, na medida em que, ao jogar futebol, as mulheres estão enveredando por um campo masculino de atuação, entendendo que, especialmente na escola, esse esporte é tido como uma prática masculina. ${ }^{47}$ Por outro lado, a subjetividade da jovem jogadora está sob ameaça, na medida em que o entendimento de que o futebol é uma prática masculina coloca sob suspeita a feminilidade das jogadoras.

A ciborguização da juventude na interface entre currículo escolar e Orkut produz escapes a esse tipo de padronização que separa homens e mulheres no que se refere às práticas esportivas. O currículo do Orkut ensina que as garotas jogam futebol e gostam.

Episódio do currículo do Orkut: descrição da comunidade do time de futebol feminino da turma de $1^{\circ}$ ano

Comunidade criada para ter informações sobre o time do futebol da turma do $1^{\circ}$ ano e agregadas.. uHuhaha Por motivos de bloqueio psicológico, o time foi eliminado do campeonato 2007 ... Mas... Ano que vem tem mais! Parabens a todas as meninas! e a torcida também!

O time de futebol feminino da turma, formado em meio às atividades do currículo escolar, mobilizou as alunas a criarem uma comunidade no Orkut para ele, mais uma evidência da interface e do contato entre as práticas escolares com as práticas ciberculturais. Isso demanda uma tradução, uma negociação dos sentidos culturais que envolvem mulheres e futebol. O currículo do Orkut ensina que as jovens gostam de jogar futebol, se entusiasmam com isso e podem ser bem-sucedidas. Na lista das comunidades relacionadas, consta a Mulheres que amam futebol, com quase 250.000 participantes. ${ }^{49} \mathrm{O}$ avatar dessa comunidade simboliza a fusão de elementos culturais tipicamente femininos e masculinos.

A imagem do avatar aciona uma hibridização que mistura elementos considerados da "cultura feminina" e outros considerados da "cultura masculina". O campo de futebol, esporte tradicionalmente atribuído aos homens, no avatar é pintado de cor-de-rosa. $O$ verde do "tapetão" é substituído pela cor atribuída às mulheres. Além disso, é o salto alto, adereço considerado tipicamente feminino na contemporaneidade, que domina a bola, substituindo a também tradicional chuteira masculina. $O$ avatar compõe uma mistura de elementos, cujo resultado não é mais facilmente localizado. Ele ocupa o "terceiro espaço",50 o intervalo entre o masculino e o feminino. É exatamente nesse lugar, na fronteira, que se situa a/o ciborgue. Ela/e contesta o que Altmann ${ }^{51}$ observou em sua pesquisa, que as imagens ligadas ao esporte na escola são masculinas e violentas, o que sugere que "o esporte é uma atividade para ser praticada por homens e que mulheres precisam adaptarse ao 'mundo masculino do esporte' para nele ingressarem".

${ }^{45}$ GOELLNER, 2000, p. 89

${ }^{46}$ GOELLNER, 2000 , p. 89.

${ }^{47}$ Helena ALTMANN, 1999.

${ }^{48}$ ORKUT, 2009.

49 ORKUT, 2009.

50 Homi BHABHA, 1998.

${ }^{51}$ ALTMANN, 1999, p. 160.

542 Estudos Feministas, Florianópolis, 19(2): 535-548, maio-agosto/201 1 
No currículo do Orkut também se ensinam coisas diversificadas e, muitas vezes, conflitantes. Isso pode ser visto na comunidade Renata Fan, da qual o aluno Tomaz do $3^{\circ}$ ano participa.

Episódio do currículo do Orkut: descrição da comunidade Renata Fan Renata Fan nasceu no dia 05/07/1977 em Santo Ângelo, Rio Grande do Sul. Formada em Direito pelo Instituto de Ensino Superior Santo Ângelo (IESA), é advogada. Atualmente é acadêmica da FIAM - Faculdades Integradas Alcântara Machado. Faz jornalismo. Renata Fan é maravilhosa, é a mulher que mais entende de futebol no momento!!!

Essa comunidade foi criada para todos os fãs que admiram sua beleza e talento e para provar que mulher também entende e muito de futebol. ${ }^{52}$

Renata Fan é a apresentadora do Jogo Aberto, um programa esportivo da Rede Bandeirantes de TV. É loira, com um corpo magro considerado belo dentro dos padrões de beleza vigentes, bronzeado, com membros torneados e barriga esculpida pela malhação, atributos que culturalmente não são vinculados à inteligência. Talvez, exatamente por isso, a descrição da comunidade citada anteriormente comece salientando a formação acadêmica da apresentadora, o que parece querer enfatizar a sua capacidade intelectual. A comunidade ainda contesta o pressuposto cultural de que mulher não entende de futebol e evoca a apresentadora como prova do contrário.

Ao apresentar a possibilidade da composição mulher-linda-gostosa-inteligente que ainda entende e gosta de futebol, o discurso do Orkut abre uma fenda, embaralha as fronteiras, divulga e disponibiliza outras subjetividades femininas. Essa subjetividade híbrida opera com elementos culturais diversos demandando a tradução entre eles, um trânsito, uma transferência dos sentidos. A juventude ciborgue pode então aprender formas divergentes de vivências das relações de gênero e se posicionar de modo a transgredir as fronteiras culturalmente estabelecidas. Desse modo, as garotas podem gostar e entender de futebol e até saber jogar.

\section{O jovem emotivo: masculinidade ameaçada}

Episódio do currículo escolar: aula de mecânica - $1^{\circ}$ ano

Durante uma aula em que a turma deveria gravar um desenho em uma caneta de metal, o aluno Márcio ( 15 anos) se acidenta em uma das máquinas e corta os dedos. 0 colega Carlos ( 15 anos) o acompanha até a pia para lavar o ferimento e cai desmaiado ao ver o sangue escorrendo na mão do amigo. Com a queda, derruba uma série de objetos e bate a cabeça no chão. O professor os socorre calmamente, se oferece para levá-los ao centro médico, os alunos se recusam. O professor então se prontifica a levá-los em casa, o que eles também rejeitam. Os alunos se comportam como se não sentissem dor.

Episódio do currículo do Orkut: tópico da comunidade da turma do $3^{\circ}$ ano $^{54}$

Momento EMO - tópico postado pelo aluno Marconi (17 anos)

Sei lah, do nada bateu a vontade de escrever isso. Soh agora a cheguei em casa a percebi q Coltec acabou, mas pretendo q as amizades ali conquistadas naum acabem. Esses dois últimos anos foram os dois melhores da minha vida (sério). Gosto muito de todos vcs, vlw galera. Ow galera vlw ai. Pode zoar de EMO, Toxo, o q for. Zoado ou querido, naum me importo, desde q naum me esqueçam. E q naum nau percamos

52 ORKUT, 2009

${ }^{53}$ Notas do diário de campo, em 10 de setembro de 2007.

${ }^{54}$ ORKUT, 2009. 
contato! Musica EMO pra acompanhar: http://www.youtube.com/watch?v=KJGFQTSCDEO [link para a música "All that I've got" da banda The Used, estilo Emocore].

Episódio do currículo do Orkut: tópico da comunidade da turma do $3^{\circ}$ ano $^{55}$

Crise EMO - tópico postado pelo aluno André (18 anos)

Aneimmmm a gente vai se separar $=c^{56}$ eu amo TODOS vcs em especial cada um de cada jeito uns mais, mais todos um tantao assim oh I-

tercero do ano passado nao buaaaaaaaaaaaaaaa $: \mathrm{l}^{57}$

Episódio do currículo do Orkut: comentários postados no fórum da comunidade do $1^{\circ}$ ano ${ }^{58}$

A aluna Lígia (16 anos) fez um vídeo com fotos da turma, colocou no YouTube e postou O link no fórum da comunidade da turma. $O$ aluno Miguel (16 anos) postou: "EXCELENTEMto legal...qse q eu choro...hauhau... Parabéns...". Lara (16 anos) disse: "chorei demais". Arthur (14 anos) também expressou seu sentimento: "foi fundo..... ow desceu ate uma lagrima aki vei..... com certeza nossa sala vi dexa saudades..... espero q daki a uns tempos todos se lembrem da histórica turma". ${ }^{59}$ Por fim, Miguel modifica o conteúdo de sua avaliação do vídeo e posta: "Galera... O povo q nunk foi numa aula nossa vai achar q nós somos todos EMOS...Creduuu...".

O termo "emo" originou-se em torno do estilo musical emotional hard core ou simplesmente emocore. Esse gênero musical inclui composições que misturam batidas fortes e letras que se referem às emoções. Além dessa atitude em relação às emoções, destacam-se, entre as/os jovens denominadas/os emos, as marcas impressas no corpo, que incluem franja, lacinhos no cabelo, meia arrastão, tênis All Star, calças xadrez, cinto de rebites, munhequeiras e alargadores auriculares. Outra marca da galera emo é a facilidade em expressar seus sentimentos, sendo comum, por exemplo, "ao se encontrarem, trocarem longos abraços, beijos e elogios. Chorar ao som de uma determinada música também faz parte". ${ }^{60} \mathrm{~A}$ atitude mais sensível tornou-as/os alvo de preconceito. "Para muitos desavisados, ser emo é sinônimo de homossexualismo". ${ }^{61}$ No Orkut há uma enormidade de comunidades que, de um modo ou de outro, abordam o universo emo. A favor, temos alguns exemplos em: EMO: se não gosta, RESPEITA; Odeio preconceito contra EMO; Eu sou EMO, sim! Algum problema?; Sou EMO e sou feliz; Sou EMO/Amo EMO; Sou EMO sim e admito. Já as comunidades contrárias podem ser vistas nos seguintes exemplos: Se EMA é BIXO, EMO é BIXA; EMO, som de fruta; ACE - Aliança Contra EMO; Eu odeio EMO. Bando de viado!; Eu odeio estilo EMO; Prefiro ser BURRO, do que ser EMO.

No discurso investigado opera-se com pressupostos da "masculinidade hegemônica", ${ }^{62}$ como não sentir dor, não chorar, não demonstrar sentimentos, ser corajoso, viril, ${ }^{63}$ forte e jamais desmaiar ao ver sangue. A masculinidade hegemônica atua como "um modelo central, enquanto outros modelos são vistos como inadequados, inferiores ou subordinados". ${ }^{64}$ Talvez por preverem um julgamento negativo de sua masculinidade, os

55 ORKUT, 2009.

${ }^{56} \mathrm{Em}$ internetês, representa uma expressão de tristeza.

${ }^{57}$ Em internetês, representa uma expressão de tristeza.

58 ORKUT, 2009.

${ }^{59} \mathrm{O}$ nome da turma foi omitido por critérios éticos.

${ }^{60}$ Juliana FERNANDEZ, 2006.

${ }^{61}$ FERNANDEZ, 2006.

${ }^{62}$ CONNELL, 1995, p. 193.

${ }^{63}$ Edinilsa Ramos SOUZA, 2005.

544 Estudos Feministas, Florianópolis, 19(2): 535-548, maio-agosto/2011 
alunos feridos na aula de mecânica recusem-se a demonstrar sua dor ou admitir a necessidade de cuidados médicos. O discurso da masculinidade hegemônica atua aí fazendo com que esses alunos conduzam suas ações em concordância com preceitos descritos na cultura sobre o correto comportamento masculino.

No currículo de mecânica investigado ensina-se a renunciar à conduta tradicionalmente definida como feminina e esconder ou suprimir as sensações de dor ou o medo de ver sangue. Tal recusa pode estar ligada ao receio de parecer efeminado. Nesse processo, uma das formas de se constituir a masculinidade é por oposição à feminilidade. ${ }^{65}$ A masculinidade se define aí mais pelo que não é, ou seja, ser homem é não ser como as mulheres. Isso significa eliminar todo um conjunto de sensações, sentimentos e necessidades culturalmente ligadas ao universo feminino. ${ }^{66}$ "Em conseqüência, confrontar a masculinidade com a feminilidade supõe rejeitar os valores que estão ligados, apenas imaginariamente, ao 'feminino', e supervalorizar os valores que estão ligados, apenas imaginariamente, ao 'masculino'". ${ }^{67}$ É preciso entender ainda que "a masculinidade é uma ficção tão histórica e culturalmente construída quanto a feminilidade, mas vivida de forma bastante diferente". 68 Desse modo, o que se relaciona culturalmente ao masculino se converte na norma por meio da qual os comportamentos são julgados. "O homem se converte no representante natural, no critério de referência a partir do qual se mede a maioria das mulheres e dos homens desvalorizados". ${ }^{69}$ E é essa a norma que vai orientar as condutas juvenis, de modo que os rapazes renunciem à possibilidade de sentir dor ou estremecer ao ver sangue.

Esse discurso que atribui o choro e o emocionar-se como próprio às mulheres e inadequado aos homens multiplica-se em nossa sociedade e circula em diversos artefatos culturais, como pode ser visto no trecho de uma revista em quadrinhos da Turma da Mônica. ${ }^{70}$ A história "Tal pai, tal filho!" se desenrola na casa da avó do Cebolinha, onde ele foi comemorar seu aniversário com a família e o amigo Cascão. De presente, Cascão entrega uma caixa para Cebolinha, que agradece: "Puxa! Valeu, cala! Eu nem sei como...". ${ }^{71}$ E abre a caixa, da qual sai voando uma borboleta. Então ele continua: "Uma bolboleta Cascão? Que lindo! Se fosse uma galota, eu cholalia!". ${ }^{72}$ Essa história também pode ensinar que chorar e se emocionar são atributos tipicamente femininos.

A construção das masculinidades, no entanto, acontece de maneira relacional, repleta de tensões e conflitos. Mesmo se apresentando como norma a ser seguida, os atributos de força, virilidade e destemor, considerados masculinos, não se impõem de modo definitivo e incontestável. Essa construção apresenta fissuras e resistências ${ }^{73}$ por parte de alguns rapazes. Na interface com o ciberespaço, alguns jovens arriscam-se e expressam seus sentimentos. Falam de suas emoções, admitem chorar ou ao menos quase chorar. Com isso acionam a masculinidade emo, ora para justificar sua conduta, ora para rejeitar aquele tipo de comportamento.

No caso analisado, a masculinidade emotiva é associada à homossexualidade e aciona uma série de preconceitos que levam à rejeição desse tipo de masculinidade,

${ }^{64}$ SOUZA, 2005, p. 60.

${ }^{65}$ SCHARAGRODSKY, 2007

${ }^{60}$ SCHARAGRODSKY, 2007.

${ }^{67}$ SCHARAGRODSKY, 2007, p. 23, tradução nossa.

${ }^{68}$ WALKERDINE, 1995 , p. 217

${ }^{69}$ SCHARAGRODSKY, 2007, p. 23

${ }^{70}$ Para uma discussão a respeito das revistas da Turma da Mônica, ver Daniela Amaral FREITAS, 2008.

${ }_{71}$ Mauricio de SOUSA, 1999, p. 6.

72 SOUSA, 1999, p. 6

${ }^{73}$ SCHARAGRODSKY, 2007 
colocando-a sob ameaça. A técnica de expressar-se de maneira emotiva, revelando os sentimentos de carinho, afeto e saudades dos pares, é categorizada como imprópria à masculinidade correta. Assim, o sentimentalismo exibido no ciberespaço é associado com a homossexualidade da figura estereotipada do emo. Em um primeiro momento, o procedimento da produção do vídeo é julgado como "EXCELENTE". Após os comentários sentimentais dos jovens, esse julgamento é reavaliado e há uma correção da conduta elogiosa. Em seguida, o procedimento adotado é de repúdio aos posts das/os colegas no tópico do Orkut: "Creduuu". Os comentários sensibilizados dos pares são rejeitados, talvez porque não condizem com a masculinidade hegemônica. A nova avaliação parece estar pautada na associação da masculinidade com a heterossexualidade como única possibilidade de vivência dos prazeres e desejos sexuais. ${ }^{74}$

O comportamento emo, originalmente ligado a um estilo musical, passa por uma espécie de "fenômeno tradutório", nos termos de Bhabha, ${ }^{75}$ e assume um novo sentido no currículo investigado. Aqui emo situa-se na fronteira entre emotivo e homossexual. A homossexualidade evocada pela figura do emo é simultaneamente desvalorizada e repudiada. O próprio jeito de ser emotivo, ainda que desvinculado da galera emo, posiciona-se na fronteira cultural que regula a maneira apropriada e correta de um homem se comportar e se expressar. Emocionar-se e, principalmente, em público não é, de modo geral, uma conduta culturalmente permitida aos rapazes.

\section{Conclusão}

A ciborguização confunde as fronteiras de gênero e reivindica posições divergentes daquelas estabelecidas culturalmente. Na interface mulher-homem e máquina, a/o ciborgue vai se produzindo de modo a questionar os padrões estabelecidos, e algumas jovens demonstram interesse e competência para jogar games eletrônicos como o Dota. Questiona-se também a impossibilidade de mulheres gostarem de futebol e saberem jogar, assim como a pretensa incompatibilidade entre os garotos e as emoções.

A subjetivação da juventude se dá em um processo repleto de disputas e conflitos. As feminilidades e as masculinidades são multiplicadas, disponibilizando diversas formas de a juventude se conduzir em termos de gênero; formas de vida juvenil marcadas pela ciborguização, pela transgressão das fronteiras culturais, pelo escape de categorizações rigidamente definidas, pelo hibridismo e pela confusão nas demarcações de gênero.

Em síntese, a pesquisa que subsidia este trabalho mostra que os discursos do currículo escolar e do Orkut se cruzam e, nesse atravessamento, vão constituindo as subjetividades juvenis generificadas, que às vezes reafirmam posturas e condutas já amplamente divulgadas em diferentes espaços sociais. Em outros momentos, as subjetividades produzidas questionam condutas e modos de ser e viver comumente aceitos na nossa sociedade. $O$ que fica evidente é que as condutas juvenis demandadas na interface do currículo escolar e do Orkut, no processo de produção da juventude ciborgue, muitas vezes transgridem as fronteiras de gênero culturalmente produzidas.

\section{Referências bibliográficas}

ALEXA. Top Sites. Disponível em: <http://www.alexa.com/topsites>. Acesso em: 28 dez. 2009. ALTMANN, Helena. "Marias (e) homens nas quadras: ocupação do espaço físico escolar". Educação \& Realidade, Porto Alegre, v. 24, n. 2, p. 157-173, jul./dez. 1999.

${ }^{74}$ BRITZMAN, 1996; e SCHARAGRODSKY, 2007.

75 BHABHA, 1998.

546 Estudos Feministas, Florianópolis, 19(2): 535-548, maio-agosto/201 1 
BHABHA, Homi. O local da cultura. Belo Horizonte: UFMG, 1998.

BRITZMAN, Deborah. "O que é essa coisa chamada amor: identidade homossexual, educação e currículo". Educação \& Realidade, Porto Alegre, v. 21 , n. 1, p. 71-96, jan./ jun. 1996.

CECCHETTO, Fátima. Violência e estilos de masculinidade. Rio de Janeiro: FGV, 2004.

CONNELL, Robert. "Políticas da masculinidade". Educação \& Realidade, Porto Alegre, v. 20, n. 2, p. 185-206, jul./dez. 1995.

DOTA BRA. Tutoriais. Disponível em: <http://dotabr.wordpress.com/category/tutoriais/>. Acesso em: 16 jan. 2008.

FERNANDEZ, Juliana. "Emos, a tribo que nasceu do punk romântico". Revista Investimentos, São Paulo, 3 maio 2006. Disponível em: <http://www.estadao.com.br/arquivo/cidades/ 2006/not200605.htm> Acesso em: 22 jul. 2008.

FOUCAULT, Michel. "Verdade e poder". In: MACHADO, Roberto (Org.). Microfísica do poder. 20. ed. São Paulo: Graal, 2004. p. 1-14.

FREITAS, Daniela Amaral. O discurso da educação escolar nas histórias em quadrinhos do Chico Bento. 2008. Dissertação (Mestrado em Educação) - Faculdade de Educação, Universidade Federal de Minas Gerais, Belo Horizonte, 2008.

GOELLNER, Silvana Vilodre. "Mulheres em movimento: imagens femininas na Revista Educação Physica". Educação \& Realidade, Porto Alegre, v. 25, n. 2, p. 77-94, jul./dez. 2000.

HARAWAY, Donna. "Manifesto ciborgue: ciência, tecnologia e feminismo-socialista no final do século XX". In: SILVA, Tomaz Tadeu da. (Org.). Antropologia do ciborgue: as vertigens do pós-humano. Belo Horizonte: Autêntica, 2000. p. 37-129.

LÉVY, Pierre. As tecnologias da inteligência: o futuro do pensamento na era da informática. São Paulo: Ed. 34, 1993.

LOURO, Guacira Lopes. "Gênero, história e educação: construção e desconstrução". Educação \& Realidade, Porto Alegre, v. 20, n. 2, p. 101-132, jul./dez. 1995.

. Gênero, sexualidade e educação: uma perspectiva pós-estruturalista. Petrópolis: Vozes, 1997.

MEYER, Dagmar. "Do poder ao gênero: uma articulação teórico-analítica". In: LOPES, Marta Júlia Marques; MEYER, Dagmar; WALDOW, Vera Regina (Org.). Gênero \& Saúde. Porto Alegre: Artes Médicas, 1996. p. 41-51.

MEYER, Dagmar; KLEIN, Carin; ANDRADE, Sandra dos Santos. "Sexualidade, prazeres e vulnerabilidade: implicações educativas". Educação em Revista, Belo Horizonte, n. 46, p. 219-239, dez. 2007

ORKUT. Disponível em: <http://www.orkut.com>. Acesso em: 10 nov. 2008.

. Disponível em: <http://www.orkut.com>. Acesso em: 28 dez. 2009.

PARAÍSO, Marlucy Alves. "A produção do currículo na televisão: que discurso é esse?". Educação e Realidade, Porto Alegre, v. 26, n. 1, p. 141-160, jan./jun. 2001.

SCHARAGRODSKY, Pablo. "Masculinidades em acción: machos, maricas, subversivos y cómplices. El caso de la Educación Física Argentina". In: RIBEIRO, Paula et al. (Org). Corpo, gênero e sexualidade: discutindo práticas educativas. Rio Grande: FURG, 2007. p. 18-30.

SCOTT, Joan. "Gênero: uma categoria útil de análise histórica". Educação \& Realidade, Porto Alegre, v. 20, n. 2, p. 71-99, jul./dez. 1995.

SILVA, Tomaz Tadeu da. O currículo como fetiche: a poética e a política do texto curricular. 2. ed. Belo Horizonte: Autêntica, 2001.

SOUSA, Mauricio de. Cebolinha. Rio de Janeiro: Globo, 1999. n. 157. 
SOUZA, Edinilsa Ramos. "Masculinidade e violência no Brasil: contribuições para a reflexão no campo da saúde". Ciência \& Saúde Coletiva, Rio de Janeiro, v. 10, n. 1, p. 59-70, 2005.

WALKERDINE, Valerie. "O raciocínio em tempos pós-modernos". Educação \& Realidade, Porto Alegre, v. 20, n. 2, p. 207-226, jul./dez. 1995.

[Recebido em 9 de fevereiro de 2011 e aceito para publicação em 10 de maio de 2011]

\section{Cyborg Youth and Gender-Border Transgression}

Abstract: People and machines are increasingly connected, by an intensely symbiotic process. Youth are especially affected by this procedure, developing a cyborg subjectivity. This article analyses the cyborging process in the interface between the school curriculum and the Orkut curriculum. The research that subsidizes this article investigated the interface between the public high school curriculum, and the communities and profiles of students from this school in Orkut. The theoretical basis is constituted by gender and curriculum studies, and the perspective is post-critical. The argument developed is that the strategies used in one curriculum can be translated into the other by the interface between them, resulting both in the transgression and the strengthening of gender borders.

Key Words: Cyborg Youth; Gender, Curriculum; Orkut. 